\title{
Pengaruh Aplikasi N, P dan K serta Pupuk Hayati terhadap P-Tersedia, Serapan P, dan Hasil Jagung Manis
}

\author{
Yanuar Euro Andrian 1), Anni Yuniarti2), dan Rina Devnita ${ }^{2)}$ \\ 1)Program Studi Agroteknologi, Fakultas Pertanian, Universitas Padjadjaran \\ 2)Departemen Ilmu Tanah dan Sumberdaya Lahan, Fakultas Pertanian Universitas Pajadjaran \\ Jl. Raya Bandung Sumedang Km 21 Jatinangor \\ Korespondensi: yanuareuro25@gmail.com
}

\begin{abstract}
Sweet corn is one of the profitable crops with high prospect in Indonesia. Unfornately corn production in Indonesia remained low. This experiment aimed to determine the effect of biofertilizer application along with $N, P$ and $K$ fertilizer Towards phosphor availability, phosphor uptake, and sweet corn yield. The research was conducted at the experimental field of Soil Chemistry and Plant Nutrition, Faculty of Agriculture, Universitas Padjadjaran, Jatinangor from October 2020 until January 2021. The experiment design was Randomized Block Design (RBD) with nine treatments consisted of one control treatment, one

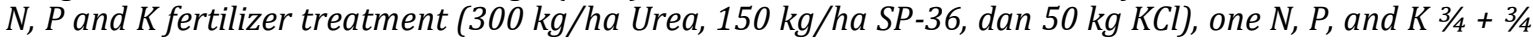
recommended biofertilizer dose, one dose of $N$, $P$, and $K 3 / 4+$ one recommended biofertilizer dose, one $N$, $P$, and $3 / 4 K$ dose $+11 / 2$ recommended biofertilizer dose, one dose of $N, P$, and one dose of $K+1 / 2$ recommended biofertilizer dose, one $N, P$, and one $K$ dose $+3 / 4$ recommended biofertilizer dose, one $N, P$, and one $K$ dose + 1 recommended biofertilizer dose, and one $N, P$, and one $K$ dose $+1 \frac{1}{2}$ recommended biofertilizer dose. The experimental results showed that combination treatments $N, P$ and $K$ fertilizer with biofertilizer has a significant impact on phosphor availability, phosphor uptake, and sweet corn yield. The $3 / 4 \mathrm{~N}, \mathrm{P}$ and $\mathrm{K}$ with one recommended biofertilizer dose, treatment showed the best result on phosphor availability $(17,23$ ppm), phosphor uptake $(0,087 \mathrm{mg} /$ plant $)$, and yield of sweet corn 474,97 g/plant.
\end{abstract}

Keywords: productivity of sweet corn, biofertilizer, cob Weighted

\section{PENDAHULUAN}

Jagung manis merupakan komoditas yang sangat digemari di Indonesia karena rasa yang manis dan memiliki kandungan vitamin A dan C (Gebhardt and Mattews, 1981 dalam Swapna et. al., 2020). Jagung manis juga mempunyai kalori yang tinggi, kadar serat tinggi dengan kadar lemak yang rendah (Swapna et. al., 2020). Prospek yang baik untuk tanaman jagung manis di Indonesia tidak diimbangi dengan produktivitas yang dihasilkan. Produktivitas jagung manis di bawah rata-rata dengan nilai 8,31 ton/ha dibandingkan kemampuan hasil jagung manis yang semestinya mencapai 14-18 ton/ha (Palungkun dan Asani, 2004).

Pupuk ialah salah satu aspek produksi yang sangat penting dalam bidang pertanian. Penggunaan pupuk harus disesuaikan dengan kebutuhan unsur hara tanaman. Pemupukan yang berlebihan dengan kebutuhan hara tanaman dan karakteristik tanah akan menyebabkan penurunan produktivitas (Kasno, 2019). Menurut Herdiyantoro dan
Setiawan (2014) penggunaan pupuk dalam jumlah berlebihan dapat mengakibatkan kerusakan kualitas tanah. Kerusakan tanah dan lingkungan tersebut dapat diatasi dengan aplikasi pupuk hayati yang dapat meningkatkan efisiensi pupuk anorganik (Setiawati dkk., 2014).

Pupuk hayati penting untuk diaplikasikan karena dapat menumbuhkan populasi jasad renik, meningkatkan daya serap air, serta mengurangi penggunaan pupuk anorganik (Rachmawati dan Korlina, 2016). Pupuk hayati sangat baik dikombinasikan dengan pupuk anorganik guna mengurangi penggunaan pupuk anorganik yang dapat merusak kualitas tanah. Menurut Puspadewi dkk. (2016) apabila pupuk $\mathrm{N}, \mathrm{P}$ dan $\mathrm{K}$ dikombinasikan bersama pupuk hayati dengan dosis yang tepat dapat menyebabkan penggunaan pupuk menjadi efisien dan dapat meningkatkan pertumbuhan tanaman. Bakteri pupuk hayati yang biasa dipakai melarutkan P sehingga dapat membuat pupuk anorganik menjadi lebih efisien adalah Pseudomonas sp. dan Bacillus sp. (Setiawati dkk., 2014). 
Inceptisols merupakan tanah muda, tetapi lebih berkembang daripada tanah Entisols, dengan penciri horizon kambik (Hardjowigeno, 2015). Inceptisols ialah ordo yang berpotensial untuk dikembangkan karena luas Inceptisols mencapai 35,5\% dari luas dataran Indonesia (Puslittanak, 2000). Menurut Abdurachman dkk. (2008) Inceptisols umumnya mempunyai taraf kesuburan yang rendah. Oleh karena itu, diperlukan pemupukan agar tingkat kesuburan tanahnya meningkat.

Menurut Solihin dkk. (2019) aplikasi pupuk $\mathrm{N}, \mathrm{P}$ dan $\mathrm{K}$ berdosis $(225 \mathrm{~kg} / \mathrm{ha} \mathrm{N}, 112,5 \mathrm{~kg} / \mathrm{ha}$ $\mathrm{P}$ dan $37,5 \mathrm{~kg} / \mathrm{ha} \mathrm{K}$ ) sangat optimal untuk meningkatkan hasil jagung manis pada Inceptisol Jatinangor. Hasil penelitian Sofatin dkk. (2016) menunjukkan bahwa aplikasi pupuk $\mathrm{N}, \mathrm{P}$ dan $\mathrm{K}$ dan pupuk hayati dapat meningkatkan hasil jagung manis sekitar 13,85 $\%$ jikadibandingkan dengan aplikasi pupuk N, P dan K saja. Suwandi dkk. (2016) menyatakan bahwa aplikasi pupuk hayati dan pupuk N, P dan $\mathrm{K}$ dapat menurunkan pemakaian pupuk $\mathrm{N}$, $\mathrm{P}$ dan K hingga 50\%. Hal ini sejalan dengan hasil penelitian Hawayanti dkk. (2015) yang menyatakan bahwa penggunaan pupuk N, P dan $\mathrm{K}$ dapat berkurang hingga $50 \%$ apabila dikombinasikan dengan pupuk hayati.

Pupuk hayati dapat menjadi alternatif pupuk yang dapat menghemat biaya produksi karena dapat mengurangi pemakaian pupuk anorganik kimia yang dapat merusak lingkungan (Wahyuni dan Parmila, 2019). Pupuk hayati perlu diperhatikan pemakaiannya karena apabila berlebihan akan menyebabkan terjadinya persaingan dalam memperoleh makanan antar mikrobanya yang berpengaruh terhadap kebutuhan nutrisi mikroba tidak terpenuhi dapat menyebabkan kinerja mikroba kurang efektif (Kalay dkk., 2020).

Aplikasi pupuk N, P dan K serta pupuk hayati dapat meningkatkan unsur hara terlarut pada tanah apabila diaplikasikan dengan dosis yang tepat. Salah satu unsur hara dengan tingkat kelarutan rendah ini adalah Fosfor (P). Kombinasi pupuk N, P dan K serta pupuk hayati diharapkan dapat meningkatkan ketersediaan $\mathrm{P}$ dalam tanah. Kebutuhan unsur hara $\mathrm{P}$ yan terpenuhi diharapkan akan meningkatkan hasil hasil jagung manis.

\section{BAHAN DAN METODE}

Penelitian dilaksanakan di Lahan Percobaan Kimia Tanah dan Nutrisi Tanaman, Fakultas Pertanian, Universitas Padjadjaran, Kampus Jatinangor Kabupaten Sumedang. Ketinggian tempat percobaan $\pm 752 \mathrm{~m} \mathrm{dpl}$. Analisis laboratorium dilaksanakan di Laboratorium Kesuburan Tanah dan Nutrisi Tanaman, Fakultas Pertanian, UNPAD.

\subsection{Alat dan Bahan}

Alat-alat yang digunakan selama penelitian dapat dibagi menjadi alat laboratorium dan alat lapangan. Alat di laboratorium yang digunakan berupa instrumen spektrofotometer untuk pengukuran P-tersedia $(710 \mathrm{~nm})$ serta serapan $\mathrm{P}(714 \mathrm{~nm})$ dan $\mathrm{pH}$ meter untuk pengukuran $\mathrm{pH}$. Peralatan tambahan yang digunakan meliputi botol kocok, mesin pengocok, dispenser, labu semprot, neraca analitik, botol kocok $50 \mathrm{ml}$, tabung reaksi, pipet $2 \mathrm{ml}$, kertas saring, oven, blender, labu kjeldahl $25 \mathrm{ml}$, dan timer. Alat yang digunakan dalam percobaan lapangan, meliputi: plang perlakuan, penggaris, meteran, alat tulis, jangka sorong, dan emrat.

Bahan-bahan yang dipakai adalah tanah Inceptisols asal Jatinangor, jagung manis varietas Paragon, pupuk Urea (N), SP 36 (P), dan $\mathrm{KCl}(\mathrm{K})$, jumlah pupuk yang digunakan disesuaikan dengan dosis perlakuan, pupuk hayati dengan dosis $5 \mathrm{ml} / \mathrm{l}$, dan pestisida berbahan aktif Sipermetrin 50 EC.

\subsection{Rancangan Percobaan}

Rancangan Acak Kelompok digunakan pada penelitian ini dengan sembilan perlakuan, yaitu:
A. Kontrol (Tanpa Pupuk)
B. Pupuk N, P, K 1 Rekomendasi
C. Pupuk N, P, K 3/4 Rekomendasi + Pupuk Hayati 3/4 Rekomendasi
D. Pupuk N, P, K 3/4 Rekomendasi + Pupuk Hayati 1 Rekomendasi 
E. Pupuk N, P, K Rekomendasi $3 / 4+$ Pupuk Hayati 11/2 Rekomendasi

F. Pupuk N, P, K 1 Rekomendasi + Pupuk Hayati $1 / 2$ Rekomendasi

G.. Pupuk N, P, K 1 Rekomendasi + Pupuk Hayati $3 / 4$ Rekomendasi

H. Pupuk N, P, K 1 Rekomendasi + Pupuk Hayati 1Rekomendasi

I. Pupuk N, P, K 1 Rekomendasi + Pupuk Hayati 11/2 Rekomendasi

Masing-masing perlakuan diulang sebanyak tiga kali, sehingga terdapat 27 satuan percobaan. Satuan percobaan berupa petakan berukuran $2 \times 3 \mathrm{~m}$.

Pengambilan contoh tanah dilakukan di sekitar perakaran (rizosfer). Tanah diambil dari lima titik (diagonal) pada masing-masing plot. Pengambilan contoh tanah dilakukan pada saat tanaman memasuki vegetatif maksimum yakni pada umur tanaman 56 HST.

Data dianalisis secara statistik menggunakan aplikasi (software) Statistical Product and Service Solutions (SPSS). Pengujian sidik ragam dilakukan dengan uji $\mathrm{F}$ (ANOVA) pada pada tingkat kepercayaan $95 \%$. Jika data menunjukkan beda nyata, maka pengujian dilanjutkan dengan uji jarak ganda Duncan pada tingkat kepercayaan $95 \%$.

\section{HASIL DAN PEMBAHASAN}

\subsection{P-Tersedia}

Hasil analisis statistik (Tabel 1) menunjukkan bahwa aplikasi pupuk N, P dan $\mathrm{K}$ serta pupuk hayati berpengaruh nyata terhadap terhadap P-tersedia. Perlakuan D, G, H, serta I merupakan perlakuan dengan hasil lebih baik dibandingkan perlakuan A, B, dan C. Hasil dari P-tersedia yang cenderung lebih baik terdapat pada perlakuan H (Pupuk N, P, K 1 + Pupuk Hayati 1) dengan nilai 17,37 ppm, dengan nilai $P$ lebih tinggi dari rata-rata semua perlakuan. Nilai P-tersedia terendah terdapat pada perlakuan kontrol (tanpa perlakuan pupuk).

Aplikasi pupuk hayati yang mengandung Bakteri Pelarut Fosfat (BPF) dengan pupuk N, P dan $\mathrm{K}$ dapat meningkatkan P-tersedia di dalam tanah. Hal ini sejalan dengan Arifin dkk. (2021) dimana aplikasi pupuk hayati pada tanah Inceptisol dapat meningkatkan P-tersedia, dengan efisiensi pemupukan 19,43\%. Bakteri Pelarut Fosfat (BPF) dapat mensekresikan asam-asam organik seperti asam format, asam laktat, asam asetat, asam malat, asam oksalat, dan asam sitrat baik unsur hara $P$ dari aktivitas pemupukan maupun yang sudah terdapat di dalam tanah (Nugraha dkk., 2019; Arifin dkk., 2021).

Tabel 1 Pengaruh pupuk N, P dan K serta Pupuk Hayati terhadap P-tersedia Tanah pada Inceptisols

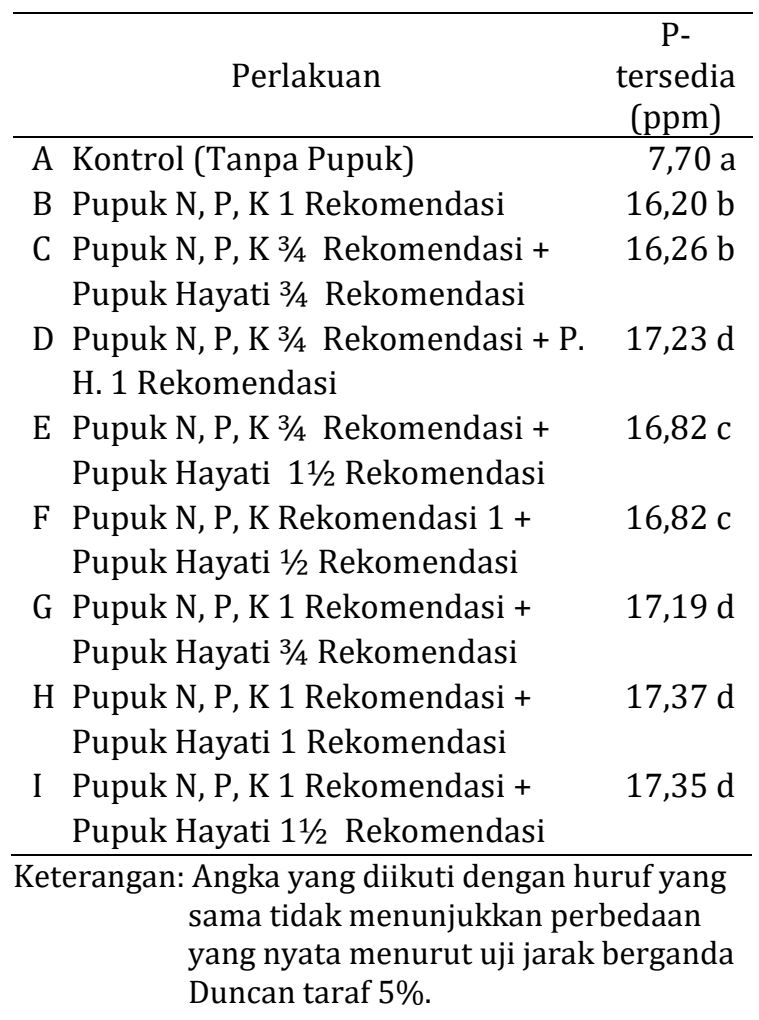

\subsection{Serapan $P$}

Hasil analisis statistik terhadap Serapan P (Tabel 2) menunjukkan terdapat pengaruh nyata pada aplikasi pupuk $\mathrm{N}, \mathrm{P}$ dan $\mathrm{K}$ serta pupuk hayati. Perlakuan kombinasi pupuk N, $\mathrm{P}$ dan $K$ dapat meningkatkan serapan $P$. Perlakuan D, G, H, dan I memiliki hasil serapan P yang lebih tinggi daripada perlakuan yang lain dengan perlakuan H Pupuk (N, P, K 1 Dosis Rekomendasi + Pupuk Hayati 1 Dosis Rekomendasi) dengan nilai 0,094 mg/tanaman 
merupakan nilai tertinggi yang berbeda nyata dengan perlakuan A (Kontrol) yang memiliki rata-rata Serapan P 0,043 mg/tanaman.

Tabel 2 Pengaruh Pupuk N, P dan K serta Pupuk Hayati terhadap Serapan $\mathrm{P}$ pada Inceptisols di Jatinangor

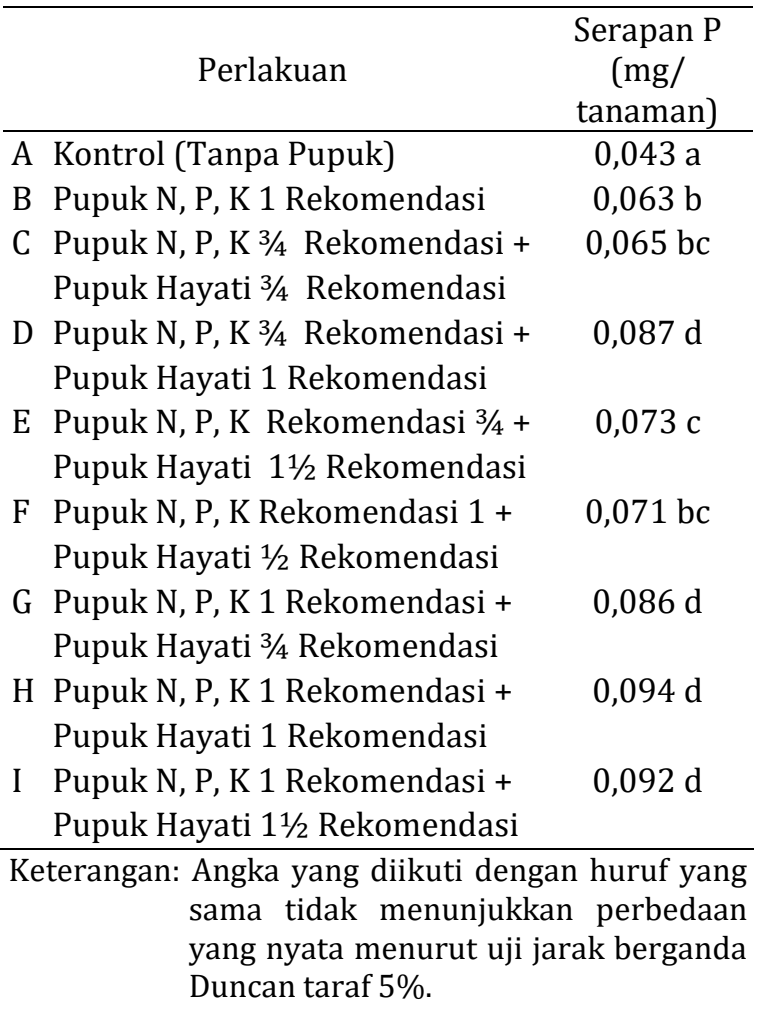

Serapan $P$ yang tinggi berhubungan dengan ketersediaan $\mathrm{P}$ di dalam tanah. Apabila P-tersedia tinggi maka serapan $\mathrm{P}$ akan ikut tinggi (Purba dkk., 2017). Hal tersebut sejalan hasil penelitian Karnilawati dkk. (2013) yang menyatakan semakin besar nilai P-tersedia maka serapan $\mathrm{P}$ tanaman akan meningkat.

\subsection{Hasil Jagung Manis}

Hasil analisis statistik terhadap hasil jagung manis (Tabel 3) menunjukkan terdapat pengaruh nyata dari pemberian pupuk N, $\mathrm{P}$ dan $\mathrm{K}$ serta pupuk hayati. Perlakuan $\mathrm{H}$ memiliki hasil tertinggi dengan rata-rata bobot tongkol berkelobot $478,27 \mathrm{~g}$, bobot tongkol kupasan $362,80 \mathrm{~g}$, diameter tongkol $55,19 \mathrm{~mm}$, dan panjang tongkol $21,08 \mathrm{~cm}$ serta perlakuan A memiliki hasil terendah dengan nilai rata-rata bobot tongkol berkelobot $344,73 \mathrm{~g}$, bobot tongkol kupasan 272,00 g, diameter tongkol $45,89 \mathrm{~mm}$, dan panjang tongkol $16,64 \mathrm{~cm}$.

Hasil panen jagung dipengaruhi beberapa faktor, salah satunya adalah lingkungan tumbuh. Iklim yang cocok dan media tanam dengan unsur hara yang cukup akan membe-rikan hasil yang baik. Selain pemupukan, pupuk hayati juga dinilai dapat meningkatkan ketersediaan unsur hara. Seperti yang dijelaskan oleh FNCA Biofertilizer Project Group (2006) dalam Sriwahyuni dan Pramila (2019), pupuk hayati mengandung mikroorganisme hidup yang dapat memperbaiki kondisi rhizosfer, meningkatkan ketersediaan unsur hara dan zat pemacu pertumbuhan.

Perlakuan H (Pupuk N, P, K 1 Dosis Rekomendasi + Pupuk Hayati 1 Dosis Rekomendasi) memiliki nilai bobot tongkol berkelobot $(478,27 \mathrm{~g})$ dan bobot tongkol kupas $(362,80 \mathrm{~g})$ tertinggi. Hal ini berhubungan dengan serapan $\mathrm{P}$ tanaman yang tinggi pada analisis sebelumnya. Semakin tinggi serapan $\mathrm{P}$ maka partumbuhan tanaman akan semakin baik, hal ini sejalan dengan hasil penelitian Harahap dan Walida (2019) bahwa semakin tinggi serapan $P$ yang terkandung di dalam tanaman maka akan meningkatkan tinggi dan bobot kering suatu tanaman.

Nilai diameter tongkol dan panjang tongkol yang cenderung lebih besar dimiliki oleh perlakuan H (Pupuk N, P, K 1 Dosis Rekomendasi + Pupuk Hayati 1 Dosis Rekomendasi) dengan nilai diameter tongkol $55,19 \mathrm{~mm}$ dan panjang tongkol 21,08 cm. Hasil ini sesuai penelitian Pangaribuan dkk. (2017) yang mendapatkan kenaikan hasil pada nilai diameter tongkol dan panjang tongkol tanaman jagung manis karena pemberian pupuk N, P dan K serta pupuk hayati.

Fosfor tersedia yang terkandung di tanah dan serapan $\mathrm{P}$ yang terkandung di daun memiliki kesinambungan dengan hasil. Menurut Ramadhani dkk. (2016) yang berperan dalam proses pembentukkan bunga sehingga mempengaruhi ukuran tongkol adalah unsur hara P. Jadi semakin banyak unsur hara P yang dikandung maka akan lebih maksimal juga pembentukkan tongkol tanaman jagung manis. 
Tabel 3 Pengaruh Perlakuan Pupuk N, P, dan K dengan Pupuk Hayati terhadap Komponen Hasil Jagung Manis

\begin{tabular}{|c|c|c|c|c|c|}
\hline & \multirow[t]{2}{*}{ Perlakuan } & $\begin{array}{c}\text { Bobot } \\
\text { Tongkol } \\
\text { Berkelobot }\end{array}$ & $\begin{array}{c}\text { Bobot } \\
\text { Tongkol } \\
\text { Kupasan }\end{array}$ & \multirow{2}{*}{$\begin{array}{c}\text { Diameter } \\
\text { Tongkol }\end{array}$} & \multirow{2}{*}{$\begin{array}{c}\text { Panjang } \\
\text { Tongkol }\end{array}$} \\
\hline & & \multicolumn{2}{|c|}{ 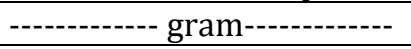 } & & \\
\hline $\bar{A}$ & Kontrol & $344,73 \mathrm{a}$ & $272,00 \mathrm{a}$ & $45,89 \mathrm{a}$ & $16,64 \mathrm{a}$ \\
\hline B & Pupuk N, P, K 1 Rekomendasi & $398,65 \mathrm{~b}$ & $325,60 \mathrm{~b}$ & $49,71 \mathrm{~b}$ & $19,05 \mathrm{~b}$ \\
\hline $\mathrm{C}$ & $\begin{array}{l}\text { Pupuk N, P, K } 3 / 4 \text { Rekomendasi + Pupuk } \\
\text { Hayati } 3 / 4 \text { Rekomendasi }\end{array}$ & $416,43 \mathrm{bc}$ & $327,13 \mathrm{~b}$ & $49,97 \mathrm{~b}$ & $19,25 \mathrm{bc}$ \\
\hline $\mathrm{D}$ & $\begin{array}{l}\text { Pupuk N, P, K 3/4 Rekomendasi + P. H. } 1 \\
\text { Rekomendasi }\end{array}$ & $474,97 \mathrm{fg}$ & $358,20 \mathrm{c}$ & $54,68 \mathrm{c}$ & $20,97 \mathrm{e}$ \\
\hline E & $\begin{array}{l}\text { Pupuk N, P, K Rekomendasi } 3 / 4+\text { Pupuk } \\
\text { Hayati Rekomendasi } 1 \frac{1}{2}\end{array}$ & 446,15 de & $347,73 \mathrm{bc}$ & $53,10 \mathrm{c}$ & $20,13 \mathrm{de}$ \\
\hline $\mathrm{F}$ & $\begin{array}{l}\text { Pupuk N, P, K Rekomendasi } 1 \text { + Pupuk } \\
\text { Hayati Rekomendasi } 1 / 2\end{array}$ & $440,67 \mathrm{~cd}$ & $343,73 \mathrm{bc}$ & $52,99 \mathrm{c}$ & $20,01 \mathrm{~cd}$ \\
\hline G & $\begin{array}{l}\text { Pupuk N, P, K } 1 \text { Rekomendasi + Pupuk } \\
\text { Hayati Rekomendasi 3/4 }\end{array}$ & 468,20 ef & $356,33 \mathrm{c}$ & $54,50 \mathrm{c}$ & $20,83 \mathrm{e}$ \\
\hline $\mathrm{H}$ & $\begin{array}{l}\text { Pupuk N, P, K } 1 \text { Rekomendasi + Pupuk } \\
\text { Hayati } 1 \text { Rekomendasi }\end{array}$ & $478,27 \mathrm{~g}$ & $362,80 \mathrm{c}$ & $55,19 \mathrm{c}$ & $21,08 \mathrm{e}$ \\
\hline I & $\begin{array}{l}\text { Pupuk N, P, K } 1 \text { Rekomendasi + Pupuk } \\
\text { Hayati 11/2 Rekomendasi }\end{array}$ & $476,40 \mathrm{fg}$ & $360,87 \mathrm{c}$ & $54,92 \mathrm{c}$ & $21,04 \mathrm{e}$ \\
\hline
\end{tabular}

\section{KESIMPULAN}

Kombinasi pupuk N, P dan K serta pupuk hayati meningkatkan P-tersedia, serapan $\mathrm{P}$, dan hasil jagung manis pada Inceptisols di Jatinangor. Kombinasi pupuk $3 / 4$ N, P, K $(225$ $\mathrm{kg} / \mathrm{ha} \mathrm{N}, 112,5 \mathrm{~kg} / \mathrm{ha} \mathrm{P}$ dan $37,5 \mathrm{~kg} / \mathrm{ha} \mathrm{K})+1$ Pupuk Hayati $(5 \mathrm{ml})$ merupakan dosis terbaik yang dapat meningkatkan P-tersedia $(17,23$ ppm), serapan $P(0,087 \mathrm{mg} /$ tanaman $)$, dan hasil jagung manis (bobot berkelobot (474,97 g), bobot tanpa kelobot $(358,20 \mathrm{~g})$, diameter tongkol $(54,68 \mathrm{~mm})$, dan panjang tongkol $(20,97 \mathrm{~cm})$.

\section{DAFTAR PUSTAKA}

Abdurachman, A., Dariah, A., dan Mulyani, A. 2008. Strategi dan teknologi pengelolaan lahan kering mendukung pengadaan pangan nasional. Jurnal Litbang Pertanian. 27(2): 43-49.

Arifin, Z., L. E. Susilowati, B. H. Kusumo, dan M. Ma'shum. 2021. Potensi pupuk hayati fosfat dalam mengefisiensi penggunaan pupuk P-anorganik pada tanaman jagung. Prosiding SAINTEK. 3: 545-554.

Harahap, F. S., dan Walida, H. 2019. Pemberian abu sekam padi dan jerami padi untuk pertumbuhan serta serapan tanaman jagung manis (Zea mays saccharata L.) pada tanah Ultisol di Kecamatan Rantau Selatan. Jurnal Agroplasma. 6(2): 12-18.

Hardjowigeno, S. 2015. Ilmu tanah. Penerbit: Akademika Pressindo.

Hawayanti, E., N. Amir, dan M. E. Exselen. 2015. Pemberian jenis pupuk hayati dan pengaruhnya terhadap pertumbuhan dan produksi tanaman jagung manis (Zea mays saccharata Sturt) di tanah lebak. Klorofil: Jurnal Penelitian Ilmu-Ilmu Pertanian, 10(1): 32-35.

Herdiyantoro, D., dan Setiawan, A. 2015. Upaya peningkatan kualitas tanah melalui sosialisasi pupuk hayati, pupuk organik, dan olah tanah konservasi di Desa Sukamanah dan Desa Nanggerang Kecamatan Cigalontang 
Kabupaten

Tasikmalaya. Dharmakarya. 4(1): 47-53.

Kalay, A. M., A. Sesa, A. Siregar, dan A. Talahaturuson. 2020. Efek aplikasi pupuk hayati terhadap populasi mikroba dan ketersediaan unsur hara makro pada tanah Entisol. Agrologia. 8(2): 63-70.

Karnilawati, K., S. Sufardi, S, dan S. Syakur. 2013. Phosfat tersedia, serapannya serta pertumbuhan jagung (Zea mays L.) akibat amelioran dan mikoriza pada Andisol. Jurnal Manajemen Sumberdaya Lahan. 2(3): 231-239.

Kasno, A. 2019. Respons tanaman jagung terhadap pemupukan Fosfor pada Typic Dystrudepts. Journal of Tropical Soils. 14(2): 111-118.

Nugraha, G. B. A., R. Wandri, dan D. Asmono. 2019. Solubilisasi Fosfat anorganik oleh Burkholderia spp. pada rizosfer kelapa sawit (Elaeis guineensis Jacq.) di tanah mineral masam. Jurnal Lahan Suboptimal. 8(1): 86-93.

Palungkun, R. dan Asanti, B. 2004. Sweet Corn Baby Corn: Peluang Bisnis, Pembudidayaan dan Penanganan Pasca Panen. Penebar Swadaya. Jakarta.

Pangaribuan, D. H., Hendarto, K., dan Prihartini, K. 2017. Pengaruh pemberian kombinasi pupuk anorganik tunggal dan pupuk hayati terhadap pertumbuhan dan produksi tanaman jagung manis (Zea mays saccharata Sturt.) serta populasi mikroba tanah. Jurnal Floratek. 12(1): 1-9.

Purba, S. T., Damanik, M. M. B., dan Lubis, K. S. 2017. Dampak pemberian pupuk TSP dan pupuk kandang ayam terhadap ketersediaan dan serapan Fosfor serta pertumbuhan tanaman jagung pada tanah Inceptisol Kwala Bekala. Jurnal Online Agroekoteknologi. 5(3): 638-643.
Puslittanak. 2000. Atlas Sumberdaya Tanah Eksplorasi Indonesia, skala 1: 000.000. Puslittanak, Badan Penelitian dan Pengembangan Pertanian. Bogor.

Puspadewi, S., Sutari, W., dan Kusumiyati, K. 2016. Pengaruh konsentrasi pupuk organik cair (POC) dan dosis pupuk $\mathrm{N}, \mathrm{P}, \mathrm{K}$ terhadap pertumbuhan dan hasil tanaman jagung manis (Zea mays L. var Rugosa Bonaf) Kultivar Talenta. Kultivasi. 15(3): 208-216.

Rachmawati, D., dan Korlina, E. 2016. Kajian penggunaan pupuk hayati untuk mengendalikan penyakit akar gada (Plasmodiophora brassicae) pada tanaman sawi daging. Agrovigor: Jurnal Agroekoteknologi. 9(1): 6772.

Ramadhani, R. H., M. Roviq, dan M. D. 2016. Pengaruh sumber pupuk nitrogen dan waktu pemberian urea pada pertumbuhan dan hasil tanaman jagung manis (Zea mays Sturt. var. saccharata). Jurnal Produksi Tanaman. 4(1): 8-15.

Swapna, G., G. Jadesha, \& P. Mahadevu. Sweet corn - a future healthy human nutrition food. Int. J. Curr. Microbiol. App. Sci. 9(7): 3859 - 3865.

Setiawati, M. R., Suryatmana, P., Hindersah, R., Fitriatin, B. N., dan Herdiyantoro, D. 2014. Karakterisasi isolat bakteri pelarut Fosfat untuk meningkatkan ketersedian P pada media kultur cair tanaman jagung (Zea mays L.). Bionatura. 16(1): 30-34.

Sofatin, S., B. N. Fitriatin, dan Y. Machfud. 2016. Pengaruh kombinasi pupuk NPK dan pupuk hayati terhadap populasi total mikroba tanah dan hasil jagung manis (Zea mays L. saccharata) pada Inceptisols Jatinangor. Soilrens, 14(2): 33-37.

Solihin, E., R. Sudirja, dan A. Yuniarti. 2019. Modifikasi pupuk N untuk 
peningkatan efisiensi penyerapan hara tanaman jagung. Jurnal Agro Wiralodra. 2(2): 60-66.

Suwandi, S., Sopha, G. A., dan Yufdy, M. P. 2016. Efektivitas pengelolaan pupuk organik, NPK, dan pupuk hayati terhadap pertumbuhan dan hasil bawang merah. Jurnal Hortikultura, 25(3): 208-221.

Wahyuni, P. S., dan Parmila, P. 2019. Peran bioteknologi dalam pembuatan pupuk hayati. Agro Bali: Agricultural Journal. 2(1): 46-57.

Yulianti, Y., Hadie, J., dan Nisa, C. 2016. Tanggapan pertumbuhan dan hasil jagung manis (Zea mays saccharata Sturt.) terhadap pemberian kapur dan pupuk kandang kotoran ayam. Daun: Jurnal Ilmiah Pertanian dan Kehutanan. 3(2): 108-121. 